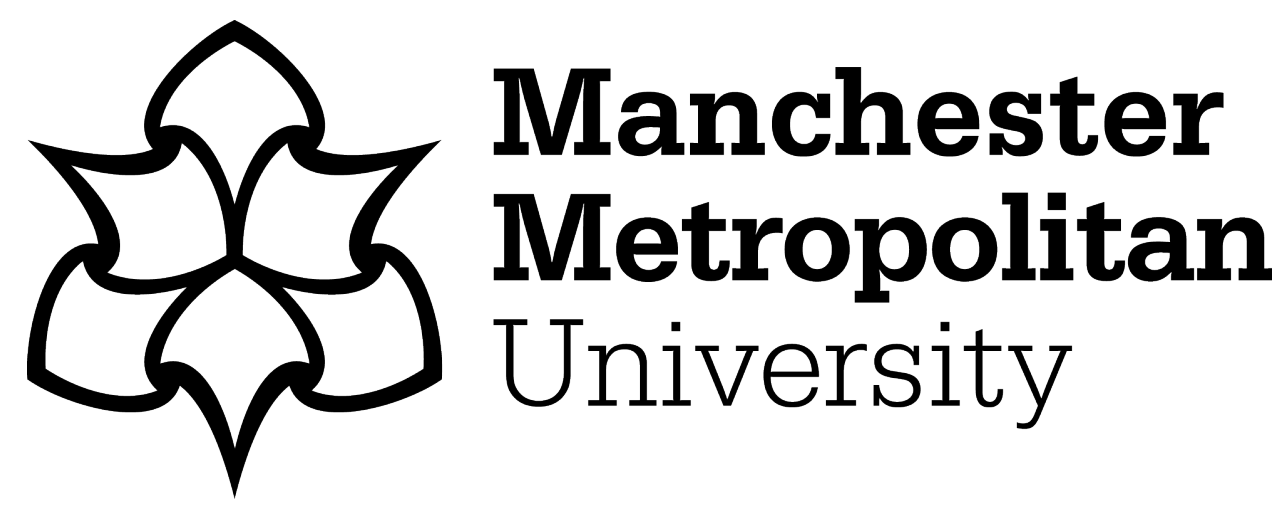

Tedesco, Silvia, Benyounis, KY and Olabi, AG (2013) Mechanical pretreatment effects on macroalgae-derived biogas production in co-digestion with sludge in Ireland. Energy, 61. pp. 27-33. ISSN 0360-5442

Downloaded from: https://e-space.mmu.ac.uk/620945/

Version: Accepted Version

Publisher: Elsevier

DOI: https://doi.org/10.1016/j.energy.2013.01.071

Please cite the published version 


\title{
Mechanical pretreatment effects on macroalgae-derived biogas production in co-digestion with sludge in Ireland.
}

\author{
S. TEDESCO*, K.Y. BENYOUNIS ${ }^{\mathrm{a}}$, A.G. OLABI ${ }^{\mathrm{b}}$ \\ *, a, b Department of Mechanical and Manufacturing Engineering, Dublin City University, \\ Glasnevin, Dublin 9, Ireland. Email: silvia.tedesco3@mail.dcu.ie
}

\begin{abstract}
Cell walls and lignin component disruption treatments are needed to enhance the hydrolytic phase and the overall biodegradability of lignocellulosics during an anaerobic digestion process. Given their abundant availability in nature, low impact on food market prices and low lignin content, aquatic plants result in being particularly suitable for biofuel conversion.
\end{abstract}

A preliminary study on the effects of a Hollander beater mechanical pretreatment has been conducted in batch mode focusing on biogas yields from five different species of Irish seaweeds in co-digestion with sludge. A second experiment on Laminaria Digitata species has been carried out using a Response Surface Methodology (RSM) with treatment times (010 minutes), mesophilic range of temperatures $\left(35-39^{\circ} \mathrm{C}\right)$ and sludge amounts (100-300 ml). Results from biogas yields of treated macroalgae have been found to be up to $20 \%$ higher when compared to untreated ones. A mathematical model of the biogas volume behaviour has been developed and the ideal conditions identified.

Keywords: Seaweeds; Anaerobic digestion; Biogas; Mechanical Pretreatment; Optimisation.

\footnotetext{
Abbreviations: ADF, Acid Detergent Fiber; ADL, Acid Detergent Lignin; ANOVA, Analysis of Variance; BT, Beating Time; COD, Chemical Oxygen Demand; HRT, Hydraulic Retention Time; NDF, Neuter Detergent Fiber; RSM, Response Surface Methodology; SA, Sludge Amount; T, Temperature; TS, Total Solids; VFA, Volatile Fatty Acids; VS, Volatile Solids; WSC, Water-soluble Carbohydrates.
} 
* Corresponding author: Department of Mechanical and Manufacturing Engineering, Dublin City University,

Glasnevin, Dublin 9, Ireland. E-mail address: silvia.tedesco3@mail.dcu.ie. Tel.: +3531 7007563

a Email: khaled.benyounis2@mail.dcu.ie

b Email: abdul.olabi@dcu.ie 


\section{Introduction}

Seaweeds as plants have much in common with their terrestrial relatives but their chemical composition differs greatly from lignocellulosic biomass. Besides being carbon neutral [1] like terrestrial plants, seaweed exploitation for bioenergy production has in particular two great advantages: aquaculture does not occupy land suitable for agriculture and growth rate is three-dimensional along height, breadth and length [2, 3]. Algae have also been found to positively contribute to higher biogas yields in co-digestion with other organic wastes $[4,5]$. The anaerobic digestion (AD) of algal waste not only recycles the nutrients but also provides biomethane, a renewable energy source [6]. Many studies from different countries have been recently considering expanding their production of biofuels using indigenous resources in order to achieve lower greenhouse gas (GHG) emissions [7-9]. A pretreatment phase is generally necessary to break down the crystalline structure of any type of plant biomass that, along with lignin, is an inhibitor and thus responsible for delaying the digestion of the cellulose and the hemicellulose [10-15]. In this respect macroalgae are better suited for the anaerobic digestion process to methane fermentation [16]. In fact, they not only have low lignin but also contain high levels of carbohydrates which make them a better feedstock for bioenergy production. Despite the low levels of lignin, macroalgal feedstock requires a mechanical pretreatment to be fully exploited [17], in order to improve and shorten the digestion cycle. In this study indigenous Irish seaweeds have been considered as substrate for pretreatment prior to anaerobic digestion.

In the literature many types of pretreatments have been performed on various substrates, while consequences to methane production were estimated [18-21]. The most used physical treatment on lignocelluloses is the thermal pretreatment, while the most used mechanical technique is milling [22]. Thermal pretreatment is very effective at enhancing both biogas yields and methane production, however due to its high temperature requirements 
it is expensive to maintain and, most importantly above certain levels of temperature, inhibiting phenomena may occur [23]. The extent of the inhibition depends on the type of substrate. Milling aims instead at reducing the particle sizes and leads to an increase of specific surface area available to microorganisms. Besides other advantages [18, 24-27], milling results in a double benefit: it reduces the digestion time by $23-59 \%$ and it causes an increase in biogas yield by 5-25\% of most lignocelluloses [19]. However, milling has high energy requirements which still limit its exploitation as the continuous rise of energy prices is not counterbalanced by significant extra gas produced [28, 29].

In our study digester sludge has been used to inoculate batch digesters with the necessary microorganisms. However, the sludge itself can be used as substrate for anaerobic digestion purposes and it currently constitutes the main organic waste for biogas production in wastewater treatment facilities. A variety of pretreatments can be applied on sludge singularly or in combination with others, with the goals of improving the methane yield and sludge's dewaterability, destroying the sludge's pathogens and reducing the odours associated with putrescible matter disposal [30]. Chemical and thermal treatments are mainly used for dewaterability improvements and pasteurization purposes, besides being associated with shorter retention times. Neyens et al. [31], for instance, show an improved sludge’s dewaterability with a 30\% reduction of the sludge volume via application of hydrogen peroxide treatment. An interesting review [32] shows the effect of thermal treatment temperature on different types of sludge, with ideal treatment temperature identified at $175^{\circ} \mathrm{C}$. Sludge’s particles disintegration was efficiently achieved by Appels et al. [33] with $40 \%$ extra biogas obtained for low frequency ultrasound treatment at $37^{\circ} \mathrm{C}$.

This paper investigates the improvements provided by a Hollander beater pretreatment. This technique is based on the same ‘comminution' concept proposed by all other mechanical treatments and increases biogas production. Due to the multiple benefits of 
exploiting the co-digestion technique $[4,5]$, a co-digestion with sludge will provide the necessary bacteria in the digesting reactors. The Hollander beater has never been used as mechanical pretreatment machine on seaweed biomass. Seeing that this proposed pretreatment has already proved its effectiveness when applied to maize silage [34] gaining up to 29\% extra biogas volume, in this study it has been applied to seaweed biomass in batch mode. The energy balance assessment at laboratory scale has been carried out and discussed in the results section.

\section{Materials and Methods}

\subsection{Pre-treatment machine characteristics}

The pre-treatment machine consists of a modified Hollander beater, model Reina in Figure 1. The machine is made of an elliptic water raceway equipped with a bladed drum spinning at 580 RPM. The energy requirement of the machine’s engine is $1 \mathrm{hp}$. A bed-plate with sharp grooves is located under the rotating wheel with dual functionality for cutting the material and decreasing the gap between blades and bed-plate. When the power is activated, blades and grooves exercise a cutting action while the high pressure and speed reached under the drum beat the mixture.

\subsection{Feedstock composition}

Algal biomass has been collected on-shore in Howth (Dublin, Ireland) in mid-January 2012 for the preliminary experiment and mid-February 2012 for the second experiment and treated the same day. The species under investigation are Pelvetia Caniculata, Fucus Serratus, Gracilaria Gracilis, Fucus Vesiculosus Linnaeus and Laminaria Digitata. The biological composition of each collected species has been provided by the Lyons Research 
Farm of University College Dublin and is shown in Table 1. Analysing Table 1 some observations were made: Laminaria Digitata species has the highest amount of water soluble carbohydrates (WSC) which is expected to speed up the digestion at least at an initial stage [35, 36]. Gracilaria Gracilis species holds the highest neutral detergent fiber content (NDF), which means more cellulose, hemicellulose and lignin but on the other hand it also contains the highest acid detergent lignin (ADL) value. Pelvetia Caniculata species has a reasonable \%NDF and \%WSC and the lowest lignin content, making it well balanced for biogas production.

\subsection{Inoculum}

Digester sludge was used as inoculum and it was collected from the anaerobic sludge vessels of the wastewater treatment plant of Celtic Anglian Water Ltd., Ringsend, Dublin. A 25 litre tank of sludge was collected the same day the experiment and used immediately. Total solids of sludge (\%TS) are very low while ammonia is high without reaching inhibitory values [37]. The sludge characterization is illustrated in Table 2.

\subsection{Bioreactors preparation}

The bioreactor system consists of flasks of $500 \mathrm{ml}$ in capacity. The equipment is constituted of: 2-way and 3-way valves, quick release tubing connectors, plastic pipes and airtight plastic bags (for biogas collection), see Figure 2. To preserve anaerobic conditions, nitrogen has been flushed for 2 minutes into the reactors to clear up any residual trace of oxygen from within the flasks and pipes, according to [38]. Water-baths were used to keep the reactors at a fixed mesophilic temperature. A biogas analyser, model Drager X-Am 3000, was used to verify anaerobic conditions were created correctly when preparing the reactors and to analyse the biogas biochemical composition. The experimental set up and methodologies are faithful to those indicated in the standard VDI 4630 [38]. 


\subsection{Experimental Methodologies}

The purpose of the first experiment is to identify whether a benefit in treating the material exists and compare each algal species 'susceptibility to the treatment. Reactors with untreated biomass were prepared with $30 \mathrm{~g}$ (wet) of each species in addition to $200 \mathrm{ml}$ of sludge. The machine was fed using $1 \mathrm{~kg}$ wet of each spp. of macroalgal biomass and 20 litres of water. After 10 minutes of pretreatment, each treated reactor is prepared with $200 \mathrm{ml}$ of algal pulp with $200 \mathrm{ml}$ of sludge (ratio 1:1). The water-bath temperature was set at $37^{\circ} \mathrm{C}$ throughout the fermentation. The experiment was performed in four replications for each species and compared with digestion of untreated samples. As a control, two digesters have been prepared with the exact amount of inoculum used in the co-digesters in order to assess the sludge contribution to the biogas formation.

The second experiment aims to find the optimal levels of factors such as the beating time (BT) of treated biomass, fermentation temperature (T) and sludge amount (SA) per reactor, while assessing how such parameters affect the biogas yield. The pretreatment was carried out on $1.6 \mathrm{~kg}$ of wet biomass with 20 litres of water. Because of its abundance, Laminaria Digitata species has been selected for this experiment, and carried out in double replication. Reactors for untreated biomass contain $15 \mathrm{~g}$ (wet) of Laminaria sp. while digesters of treated samples are filled with $200 \mathrm{ml}$ of algal pulp; these samples were used for each permutation of the varying factors.

The moisture content of both untreated and treated material has been calculated to provide a comparison per gram of total solids (TS = 1 - moisture content (\%)). The moisture content of untreated samples is a weighted average determined by drying random weights. The moisture content of the treated samples was obtained by drying $200 \mathrm{ml}$ of macralgal pulp in both the experiments. The drying was performed at $105^{\circ} \mathrm{C}$ until constant weight. Moisture 
content findings of the first experiment are shown in Table 1. The moisture contents of the second experiment were found to be $83.2 \%$ for the untreated samples, $98.9 \%$ for samples treated for 5 minutes and $99.0 \%$ for samples treated for 10 minutes. After the incubation, flasks were gently shaken every 20 hours in order to favour the degasification of the substrate and the contact between the biomass and the inoculum [38]. When the biogas production rate was found to be less than $1 \%$ of the overall volume produced, the digestion was stopped according to [38]. Hydraulic retention time (HRT) was 21 days.

\subsection{Design of Experiment (DOE)}

The conditions to be tested in the second experiment were planned according to a response surface methodology (RSM) for three factors with three levels. This methodology was then applied to the measured yields using the statistical software, Design-Expert v.8. RSM is a set of mathematical and statistical techniques that are useful for modelling, interpreting and predicting the response of interest to several input variables $\chi$ (from level i to j) with the aim of optimizing a response " $y$ ", which in this case is the biogas volume. As the inoculum was collected from a wastewater digester constantly operating at the stable regime of $37^{\circ} \mathrm{C}$, it was decided to study the biogas yield from fluctuations within a small range of that temperature.

Independent input variables and factor levels are respectively 0, 5, 10 minutes for the beating time $\mathrm{BT} ; 35^{\circ} \mathrm{C}, 37^{\circ} \mathrm{C}$ and $39^{\circ} \mathrm{C}$ as temperatures $\mathrm{T}$ for the mesophilic range; and finally 100, 200 and 300ml of sludge amounts SA. Level 0 of factor BT represents untreated biomass. The experiment was planned based on a three level Box-Behnken design with full replication. Second order polynomials were fitted to the experimental data to obtain the regression equations. The sequential F-test, lack-of-fit test and other adequacy measures were used in selecting the best models. A step-wise regression method was used to fit the second 
order polynomial Eq. (1) to the experimental data and to identify the relevant model terms [39-41]. The same statistical software was used to generate the response plots. The values of the coefficients $b_{0}, b_{i}, b_{i i}$ and $b_{i j}$ can be calculated using regression analysis.

$$
\mathrm{Y}=b_{o}+\sum b_{i} \chi_{i}+\sum b_{i i} \chi_{i i}^{2}+\sum b_{i j} \chi_{i} \chi_{j}
$$

The Probability $>F$ (sometimes called $p$-value) of the model and of each term in the model can be computed by means of analysis of variance (ANOVA). If the Prob. $>F$ of the model and of each term in the model does not exceed the level of significance (in this case $\alpha=0.1)$ then the model may be considered adequate within the confidence interval of $(1-\alpha)$. An adequate model means that the reduced model has successfully passed all the required statistical tests and can be used to predict the responses or to optimize the process [41]. Results are then used to run an optimization study using the numerical and graphical methods provided by Design-Expert in order to find out the best factors levels that, under specific user-defined criteria, will maximize the biogas production.

\section{Results and Discussion}

\subsection{Biogas production}

Results of the biogas collections of the preliminary experiment are presented in Table 3. An average of $383.5 \mathrm{ml}$ is produced by the sludge control during 21 the days, which represents the sludge contribution to the biogas formation. Analysis of data in Table 3 shows that treated samples produce higher biogas volumes; this is attributed to an improved availability of the substrate's surface to the microorganisms of the sludge due to the pretreatment. In particular, the most productive species appear to be Pelvetia Caniculata and the two Fucus species with respectively about $71 \%$ and $69 \%$ extra biogas produced by treated samples. The reasons of this can be identified in the composition of such species illustrated in 
Table 1. Pelvetia Caniculata is the one with the lowest lignin content (lignin being an inhibitor), while the two Fucus spp. have the medium-high level of neutral fibers, which means high biogas potential.

Results of the second experiment are shown in Table 4 according to the RSM design matrix, sorted by standard order. All samples contained an amount of methane of about $40 \%$ of the biogas volume. These consistent results are due to the small range of temperature chosen for the experiment that do not greatly influence the methane content. Results of Laminaria sp. biogas production of the first experiment and biogas produced by untreated samples 1, 2, 9 and 11 in Table 4, are in line with the biogas yields achieved by Hanssen et al. [42] at the incubation temperature of $35^{\circ} \mathrm{C}$. This suggests that the temperature will not consistently affect the biogas response of the RSM study. Sample 12 was treated in the Hollander beater for 10 minutes prior to incubation at $37^{\circ} \mathrm{C}$. This sample produced a biogas volume of $577 \mathrm{~mL} \mathrm{gTS}^{-1}$, which is about $10 \%$ lower than Hanssen’s best result achieved on Laminaria Saccharina (yield $460 \mathrm{~mL} \mathrm{gVS}^{-1}$ ) when chopping was used as pretreatment and cattle manure as inoculum [42]. This paper's results confirm that sludge acts equally or even better, than animal manures or anaerobic marine environment derived inocula [42, 43].

\subsection{Model estimation}

The fit summary output of the full RSM indicates that the linear model is statistically significant for the volume response. The resulting analysis of variance (ANOVA) for the reduced quadratic model shows the model terms of $\mathrm{R}^{2}$, adjusted $\mathrm{R}^{2}$ and adequate precision are respectively $0.90,0.87$ and $17.9 . \mathrm{R}^{2}$ and adjusted $\mathrm{R}^{2}$ are very close to 1 and so indicate an adequate model has been estimated. The achieved adequate precision is $>>$ than 4 , which indicates good model discrimination. 
The analysis of variance indicates that the beating time (BT), the sludge amount (SA), the two level interaction of beating time and sludge amount (BT x SA) and the second order effect of beating time (BT) are the most significant factors affecting the biogas volume. The predicted vs. actuals plot is shown in Figure 3a. This figure indicates that the developed models are adequate because the residuals are minimal, since they tend to be close to the diagonal line. The normal plot of residuals in Figure 3b demonstrates that the assumption of normal distribution of the data is respected; therefore the ANOVA can be applied to study the dataset. The biogas yields of the full RSM experiment associated to their standard deviations are shown in Figure 4. The standard deviations identified provide the interval of confidence of the biogas measurements. Sample 6 and 9 present the highest standard deviations, meaning those samples reading are less reliable and thus may slightly vary whether the experiment would be repeated. The final mathematical model associated to the response in terms of coded factors and actual factors determined by the software are respectively eq. (2) and (3).

Biogas Volume $=282.8-25.9 \mathrm{BT}+142.5 \mathrm{SA}+82.5 \mathrm{BT} \mathrm{SA}+96.6 \mathrm{BT}^{2}$

Biogas Volume $=285.4-76.8 \mathrm{BT}-0.6 \mathrm{SA}+0.2 \mathrm{BT} \mathrm{SA}+3.4 \mathrm{BT}^{2}$

The response surface so obtained is illustrated in Figure 5. The perturbation plot in Figure 6a shows how the biogas yield is only affected by the input variables BT and SA. Factor $\mathrm{T}$ is almost insignificant to the response variation and thus does not appear in such figure, while increasing SA will in turn consistently improve the response. The temperature generally affects the stability of an $\mathrm{AD}$ process, however in this case $\pm 2^{\circ} \mathrm{C}$ variations do not meaningfully alter the growth rate of bacteria. A wider range of temperatures will be thus considered in future work, spanning from psychrophilic to thermophilic temperatures. Factor BT also affects the response following a quadratic behaviour. The interaction plot in Figure $6 \mathrm{~b}$ shows the effect of the combined action of SA and BT on the biogas yield. This 
interaction acts in such a way that the effect of the pretreatment is very positive when SA is over $230 \mathrm{ml}$. Finally, the biogas production increases linearly when crescent SA is used.

\subsection{Biogas yield's optimisation}

In order to predict the best factor levels that will maximize the biogas production; the optimizing function consists of the maximization of eq. (2) and (3). A numerical optimisation provided by Design-Expert was applied to the RSM dataset, followed by a graphical optimization. The numerical study will provide the ideal factor levels to achieve the highest biogas yield, while the graphical method investigation will result in a chart that associates the factor levels to an area of target yields defined by the user.

The optimisation was conducted with numerical restricting criteria. Temperature was constrained to $35^{\circ} \mathrm{C}$ for cost saving on the heating units, seeing that temperature was not a significant varying factor. Factors BT and SA were left in range as the second experiment. The numerical solutions identified by design-expert were 38, while the highest yield numerically calculated corresponds to $579 \mathrm{~mL} \mathrm{gTS}^{-1}$ and is achieved at $\mathrm{T}=35^{\circ} \mathrm{C}, \mathrm{SA}=300 \mathrm{ml}$ and BT=10 minutes. The optimised solution of treated material presents an increase in biogas volume of about $20 \%$ compared to the highest untreated yield. As biochemical composition of Laminaria spp. is subjected to the seasonal variation, even higher biogas yields are expected when the pretreatment is applied to feedstock harvested in late summer/autumn [44, 45].

Finally, the graphical optimisation's findings are shown in Figure 7 at $\mathrm{T}=35^{\circ} \mathrm{C}$. The target area (in yellow) is delimited by two curves corresponding to the maximizing criteria set 
by the authors. Lower and upper limits of such area are respectively the lowest (417 mL gTS ${ }^{1}$ ) and the highest (579 $\mathrm{mL} \mathrm{gTS}^{-1}$ ) biogas yields identified by Design-Expert in the numerical optimization. Figure 7 offers a quick-approach chart to obtain operational parameters for macroalgal-based reactors in co-digestion with sludge.

\subsection{Energy balance evaluation}

In order to evaluate the economic feasibility at lab scale of the Hollander beater treatment, the specific energy consumption was calculated and compared with the biogas energy produced. Results of the energy assessment are calculated in MJ/kgTS [46]. The energy balance assessment was carried out for the optimum condition found in the RSM which is sample 12 (10 minutes). The methane content of this sample was found to be about $40 \%$.

The machine's maximum energy input is 1hp. In order to evaluate the effective consumption, the treatment's energy was estimated by using a commercial volt meter, and was found to be $0.06 \pm 0.01 \mathrm{KWh}$ which means about $0.8 \mathrm{MJ} / \mathrm{kgTS}$. If the digestion is carried out at the same incubating conditions as sample 12 for all treated macroalgal pulp, the resulting specific energy production would be $7.9 \mathrm{MJ} / \mathrm{kgTS}$, with about $90 \%$ energy gain corresponding to $7.1 \mathrm{MJ} / \mathrm{KgTS}$. These results do not include the extra energy deriving from the sludge's biogas contribution, which would enhance even more the energy gain.

\section{Conclusions}

Our experimental work shows the biogas yields obtained from co-digestion of seaweed biomass with digester sludge. A mechanical pretreatment has been applied to the 
macroalgal feedstock by using a Hollander beater, and results of biogas volume rates compared to digestion of sludge-only and co-digestion of untreated biomass. Performance tests on untreated and treated samples prove the proposed pretreatment increases the biodegradation effectiveness. Results show that some species of macroalgae are preferable to others. Pelvetia Caniculata, Fucus Vesiculosus and Fucus Serratus give the best volume rates and will be further investigated. The ideal ratio of algal pulp and SA has been identified as 2:3; at this ratio an improvement of up to $20 \%$ of extra biogas can be obtained when using this pretreatment for 10 minutes of beating time. The energy assessment at 10 minutes treatment time indicates that a positive energy gain of $90 \%$ can be achieved at the net of the Hollander beater energy requirements. Further work will focus on expanding the range of parameters to characterize better the system.

\section{Acknowledgements}

This research was supported by the Irish Research Council for Science, Engineering and Technology (IRCSET), funded by the National Development Plan.

\section{References}

[1] Saxena RC, Adhikari DK, Goyal HB. Biomass-based energy fuel through biochemical routes: A review. Renewable Sustainable Energy Rev. 2009;13:167-78.

[2] Tedesco S, Olabi AG. Review of lignocellulosic material as bioenergy source with applications to anaerobic digestion and CHP. In Olabi AG, Benyounis KY, editors. ICAE 2012: Proceedings of the International conference on Applied Energy; 2011 May 16-18; Perugia, Italy. Tree; 2011. p. 513-22.

[3] Singh A, Singh Nigam P, Murphy JD. Renewable fuels from algae: An answer to debatable land based fuels. Bioresour. Technol. 2011;102:10-6. 
[4] Yen HW, Brune DE. Anaerobic co-digestion of algal sludge and waste paper to produce methane. Bioresour. Technol. 2007; 98:130-4.

[5] Matsui T, Koike Y. Methane fermentation of a mixture of seaweed and milk at a pilot scale-plant. J. Biosci. Bioeng. 2010; 110:558-63.

[6] Singh A, Olsen SI. A critical review of biochemical conversion, sustainability and life cycle assessment of algal biofuels. Appl. Energy 2011; 88:3548-55.

[7] Budzianowski WM. Target for national carbon intensity of energy by 2050: A case study of Poland's energy system. Energy 2012; 46:575-81.

[8] Sana V, Srivb T, Spoanna V, Vara S, Seak S. Economic and environmental costs of rural household energy consumption structures in Sameakki Meanchey district, Kampong Chhnang Province, Cambodia. Energy 2012, In press: http://dx.doi.org/10.1016/j.energy.2012.10.017

[9] Schneider DR, Kirac M, Hublin A. Cost-effectiveness of GHG emission reduction measures and energy recovery from municipal waste in Croatia. Energy 2012, In press, http://dx.doi.org/10.1016/j.energy.2012.02.008

[10] Hendriks ATWM, Zeeman G. Pretreatments to enhance the digestibility of lignocellulosic biomass. Bioresour. Technol. 2009;100:10-8.

[11] Pérez J, Muñoz-Dorado J, De La Rubia T, Martínez J. Biodegradation and biological treatments of cellulose, hemicellulose and lignin: an overview. Int. Microbiol. 2002;5:53-63.

[12] Barakat A, Monlau F, Steyer JP, Carrere H. Effect of lignin-derived and furan compounds found in lignocellulosic hydrolysates on biomethane production. Bioresour. Technol. 2012;104:90-9.

[13] Tiolo JM, Sommer SG, Møller HB, Weisbjerg MR, Jiang XY. A new algorithm to characterize biodegradability of biomass during anaerobic digestion: Influence of 
lignin concentration on methane production potential. Bioresour. Technol. 2011;102: 9395-402.

[14] Nizami AS, Korres NE, Murphy JD. Review of the integrated process for the production of grass biomethane. Environ. Sci. Technol. 2009;43:8496-508.

[15] Zhu L, O’Dwyer JP, Chang VS, Granda CB, Holtzapple MT. Structural features affecting biomass enzymatic digestibility. Bioresour. Technol. 2008; 99:3817-28.

[16] Chynoweth DP, Owens JM, Legrand R. Renewable methane from anaerobic digestion of biomass. Renewable Energy 2001; 22:1-8.

[17] Gurung A, Van Ginkel SW, Kang WC, Qambrani NA, Oh SE. Evaluation of marine biomass as source of methane in batch test: A lab-scale study. Energy 2012; 43:396401.

[18] Agbor VB, Cicek N., Sparling R, Berlin A, Levin DB. Biomass pretreatment: Fundamentals towards application. Biotechnol. Adv. 2011; 29:675-85.

[19] Hendriks ATWM, Zeeman G. Pretreatments to enhance the digestibility of lignocellulosic biomass. Bioresour. Technol. 2009;100:10-8.

[20] Taherzadeh MJ, Karimi K. Pretreatment of Lignocellulosic Wastes to Improve Ethanol and Biogas Production: A Review. Int. J. Mol. Sci. 2008;9:1621-51.

[21] Mtui GYS. Recent advances in pretreatment of lignocellulosic wastes and production of value added products. Afr. J. Biotechnol. 2009;8:1398-415.

[22] Carsson M, Lagerkvist A, Morgan-Sagastume F. The effects of substrate pretreatment on anaerobic digestion systems: A review. Waste Manage. 2012;32:163450.

[23] Rafique R, Poulsen TG, Nizami AS, Asam ZUZ, Murphy JD, Kiely G. Effect of thermal, chemical and thermo-chemical pre-treatments to enhance methane production. Energy 2010; 35:4556-661. 
[24] Delgenes JP, Penaud V, Moletta R. Pretreatments for the enhancement of anaerobic digestion of solid wastes. In: Mata-Alvarez J, editor. Biomethanization of the Organic Fraction of Municipal Solid Wastes, London IWA Publishing; 2003.

[25] Kim J, Park C, Kim TH, Lee M, Kim S, Kim SW, Lee J. Effects of various pretreatments for enhanced anaerobic digestion with waste activated sludge. J. Biosci. Bioeng. 2003;95:271-5.

[26] Palmowski L, Muller J. Influence of the size reduction of organic waste on their anaerobic digestion. II International Symposium on Anaerobic Digestion of Solid Waste 1999, Barcelona, 137-44.

[27] Palmowski L, Muller J. Influence of comminution of biogenic materials on their bioavailability. Muell Abfall 1999;31:368-72.

[28] Cowling EB, Kirk TK. Properties of cellulose and lignocellulosic material as substrates for enzymatic conversion processes. T. K. Biotechnology Bioengineering Symposium 1976; 6:95-123.

[29] Ramos LP. The chemistry involved in the steam treatment of lignocellulosic materials. Quím. Nova 2003; 26: available online at http://dx.doi.org/10.1590/S010040422003000600015

[30] Appels L, Dewil R, Baeyens J, Degrève J. Principles and potential of the anaerobic digestion of waste-activated sludge. Prog. Energy Combust. Sci. 2008;34:755-81.

[31] Neyens E, Baeyens J. A review of classic Fenton’s peroxidation as an advanced oxidation technique. J. Hazard. Mater. 2003;98:33-50.

[32] Neyens E, Baeyens J. A review of thermal sludge pre-treatment processes to improve dewaterability. J. Hazard. Mater. 2003;98:51-67.

[33] Appels L, Baeyens J, Degrève J, Dewil R. Ultrasonically enhanced anaerobic digestion of waste activated sludge. Int. J. Sustainable Eng. 2008;1:94-104. 
[34] Mohammed A, Alfarjani F, Benyounis KY, Prescott T, Olabi AG. Application of mechanical pretreatment to produce methane from Maize. Int. Conf. of Efficiency, Cost, Optimization, Simulation and Environmental Impact of Energy Systems (ECOS) 2011, Novi Sad, pp. 3595-602.

[35] Downing TW, Buyserie A, Gamroth M, French P. Effect of Water Soluble Carbohydrates on Fermentation Characteristics of Ensiled Perennial Ryegrass. Professional Animal Scientist 2008; 24:35-9.

[36] Yang HY, Wang XF, Liu JB, Gao LJ, Ishii M, Igarashi Y, Cui ZG. Effects of watersoluble carbohydrate content on silage fermentation of wheat straw. J. Biosci. Bioeng. 2006;101:232-7.

[37] Chen Y, Cheng JJ, Creamer KS. Inhibition of anaerobic digestion process: A review. Bioresour. Technol. 2008; 99:4044-64.

[38] Verein Deutscher Ingenieure, VDI 4630, Düsseldorf, 2006.

[39] Benyounis KY, Olabi AG, Hashmi MSJ. Effect of laser welding parameters on the heat input and weld-bead profile. J. Mater. Process. Technol. 2005;164-165: 978-85.

[40] Eltawahni HA, Hagino M, Benyounis KY, Inoue T, Olabi AG. Effect of $\mathrm{CO}_{2}$ laser cutting process parameters on edge quality and operating cost of AISI316L. Opt. Laser Technol. 2012; 44:1068-82.

[41] Eltawahni HA, Olabi AG, Benyounis KY. Investigating the $\mathrm{CO}_{2}$ laser cutting parameters of MDF wood composite material. Opt. Laser Technol. 2011;43:648-59.

[42] Hanssen JF, Indergaard M, Østgaard K, Baeve OA, Pedersen TA, Jensen A. Anaerobic digestion of Laminaria spp. and Ascophyllum nodosum and application of end products. Biomass 1987;14:1-13. 
[43] Chynoweth D P, Ghosh S, Klass, DL, 1981. Anaerobic digestion of kelp. In: Biomass Conversion Processes for Energy and Fuels, Sorer, S. S. \& Zaborsky, O. R. (eds), Plenum Press, N.Y., pp. 315-38.

[44] Haug, A, Jensen, A, 1954. Seasonal variations in chemical composition of Alaria esculenta, Laminaria saccharina, Laminaria hyperborea and Laminaria digitata from Northern Norway. Norw. Inst. Seaweed Res., Report No. 4, Trondheim.

[45] Adams JMM, Toop TA, Donnison IS, Gallagher JA. Seasonal variation of Laminaria digitata and its impact on biochemical conversion routes to biofuels. Bioresour. Technol. 2011;102:9976-84.

[46] Zhu JY, Pan XJ. Woody biomass pretreatment for cellulosic ethanol production: Technology and energy consumption evaluation. Bioresour. Technol. 2010;101:49925002. 


\section{Table Captions:}

Table 1: Composition of macroalgal species with related moisture content of untreated and treated samples.

Table 2: Sludge characterization (Celtic Anglian Water Ltd.).

Table 3: Preliminary experiment results of biogas yields of treated and untreated samples.

Table 4: Design matrix and measured biogas yields.

\section{Figure Captions:}

Fig. 1: Hollander beater's working scheme and machine used in the experiment.

Fig. 2: Heating units with reactors and collection bags.

Fig. 3: Scatter diagrams of biogas yields (a) and normal plot of residuals (b).

Fig. 4: Bar-diagram of biogas yields with standard deviation values.

Fig. 5: Response surface plot for biogas yield.

Fig. 6: Perturbation plot (a) show the effect of process parameters on biogas volume;

Interaction plot (b) showing the effect between sludge amount (SA) and beating time (BT) on response.

Fig. 7: Optimum zone with highest software-estimated biogas yields between $417 \mathrm{~mL} \mathrm{gTS}^{-1}$ and $579 \mathrm{~mL} \mathrm{gTS}^{-1}$ at $\mathrm{T}=35^{\circ} \mathrm{C}$. 
Table 1 Composition of macroalgal species with related moisture content of untreated and treated samples.

\begin{tabular}{|c|c|c|c|c|c|c|c|c|}
\hline Species & $\% \mathbf{M C}^{\mathrm{a}}$ untreated & $\% \mathrm{MC}^{\mathrm{a}}$ treated & \%Ash & \%Nitrogen & $\% \mathrm{NDF}^{\mathrm{b}}$ & $\% \mathrm{ADF}^{\mathrm{c}}$ & $\%$ ADL $^{d}$ & $\% W_{S C}$ \\
\hline $\begin{array}{l}\text { Laminaria } \\
\text { Digitata }\end{array}$ & 78.2 & 99.3 & 19.5 & 3.3 & 25.7 & 22.3 & 12.1 & 4.4 \\
\hline $\begin{array}{c}\text { Gracilaria } \\
\text { Gracilis }\end{array}$ & 77.3 & 99.6 & 16.6 & 2.6 & 53.6 & 46.6 & 25.3 & 0.3 \\
\hline $\begin{array}{c}\text { Fucus } \\
\text { Vesiculosus }\end{array}$ & 78.2 & 99.2 & 19.6 & 1.9 & 35.3 & 28.1 & 16.4 & 0.9 \\
\hline $\begin{array}{c}\text { Fucus } \\
\text { Serratus }\end{array}$ & 80.0 & 99.3 & 18.5 & 2.2 & 29.6 & 27.5 & 17.1 & 1.1 \\
\hline $\begin{array}{l}\text { Pelvetia } \\
\text { Caniculata }\end{array}$ & 78.8 & 99.2 & 19.1 & 1.5 & 25.7 & 15.1 & 7.5 & 1.3 \\
\hline
\end{tabular}

${ }^{\mathrm{a}} \mathrm{MC}=$ moisture content.

${ }^{b}$ Neutral-detergent Fiber.

${ }^{c}$ Acid-detergent Fiber.

${ }^{d}$ Acid-detergent Lignin.

${ }^{e}$ Water-soluble Carbohydrates. 
Table 2 Sludge characterization (Celtic Anglian Water Ltd.).

\begin{tabular}{lc}
\hline \multicolumn{1}{c}{ Sludge } \\
\hline \multicolumn{1}{c}{ Parameters } & Value \\
\hline Total Solids (TS) [\%] & 5.6 \\
Volatile Solids (VS) [\%] & 72.0 \\
COD ${ }^{\mathrm{a}}$ [mg/l] & 65.5 \\
Ammonia [mg/l] & 2.8 \\
Alkalinity [mg/l] & 12.1 \\
VFA's ${ }^{\mathrm{b}}$ [mg/l] & 42.0 \\
\hline${ }^{a}$ COD $=$ Chemical Oxygen demand. \\
${ }^{b}$ VFA $=$ Volatile fatty acids.
\end{tabular}


Table 3 Preliminary experiment results of biogas yields of treated and untreated samples.

\begin{tabular}{ccc}
\hline $\begin{array}{c}\text { Biogas produced } \\
\text { from untreated } \\
\text { species }{ }^{*} \pm \text { STD } \\
\text { [mL } \text { gTS }^{-1} \text { ] }\end{array}$ & $\begin{array}{c}\text { Biogas produced } \\
\text { treated } \\
\text { species }{ }^{*} \pm \text { STD } \\
\text { [mL } \text { gTS }^{-1} \text { ] }\end{array}$ & Species \\
\hline $159.3 \pm 24.0$ & $444.3 \pm 13.4$ & Pelvetia Caniculata \\
$64.2 \pm 21.1$ & $181.2 \pm 28.3$ & Fucus Serratus \\
$81.8 \pm 32.5$ & $171.8 \pm 27.6$ & Gracilaria Gracilis \\
$71.5 \pm 4.9$ & $230.5 \pm 25.5$ & Fucus Vesiculosus \\
$103.3 \pm 19.8$ & $156.4 \pm 16.7$ & Linnaeus \\
\hline
\end{tabular}

*Incubation at $37^{\circ} \mathrm{C}$ after 21 days with standard deviation (STD) values. 
Table 4 Design matrix and measured biogas yields.

\begin{tabular}{lccc|c}
\hline \multicolumn{4}{c|}{ Design matrix $^{\mathbf{a}}$} & Response \\
\hline Exp. No. & $\begin{array}{c}\text { Temperature } \\
{\left[{ }^{\circ} \mathbf{C}\right]}\end{array}$ & $\begin{array}{c}\text { Beating Time } \\
\text { [minutes] }\end{array}$ & $\begin{array}{c}\text { Sludge Amount } \\
\text { [mL] }\end{array}$ & $\begin{array}{c}\text { Volume } \\
\text { [mL } \text { gTS }^{-1} \text { ] }\end{array}$ \\
\hline 1 & & & 200 & 356.4 \\
2 & 35 & 0 & 200 & 415.8 \\
3 & 39 & 0 & 200 & 287.6 \\
4 & 35 & 10 & 200 & 376.0 \\
5 & 39 & 10 & 100 & 145.2 \\
6 & 35 & 5 & 100 & 152.6 \\
7 & 39 & 5 & 300 & 435.8 \\
8 & 35 & 5 & 300 & 524.9 \\
9 & 39 & 5 & 100 & 387.7 \\
10 & 37 & 0 & 100 & 173.4 \\
11 & 37 & 10 & 300 & 461.2 \\
12 & 37 & 0 & 300 & 577.1 \\
13 & 37 & 10 & 200 & 238.8 \\
14 & 37 & 5 & 200 & 281.2 \\
15 & 37 & 5 & 200 & 255.0 \\
16 & 37 & 5 & 200 & 245.2 \\
17 & 37 & 5 & 200 & 266.4 \\
\hline${ }^{a}$ Each condition has been replicated with $n=2 ;$ resulting response was averaged.
\end{tabular}




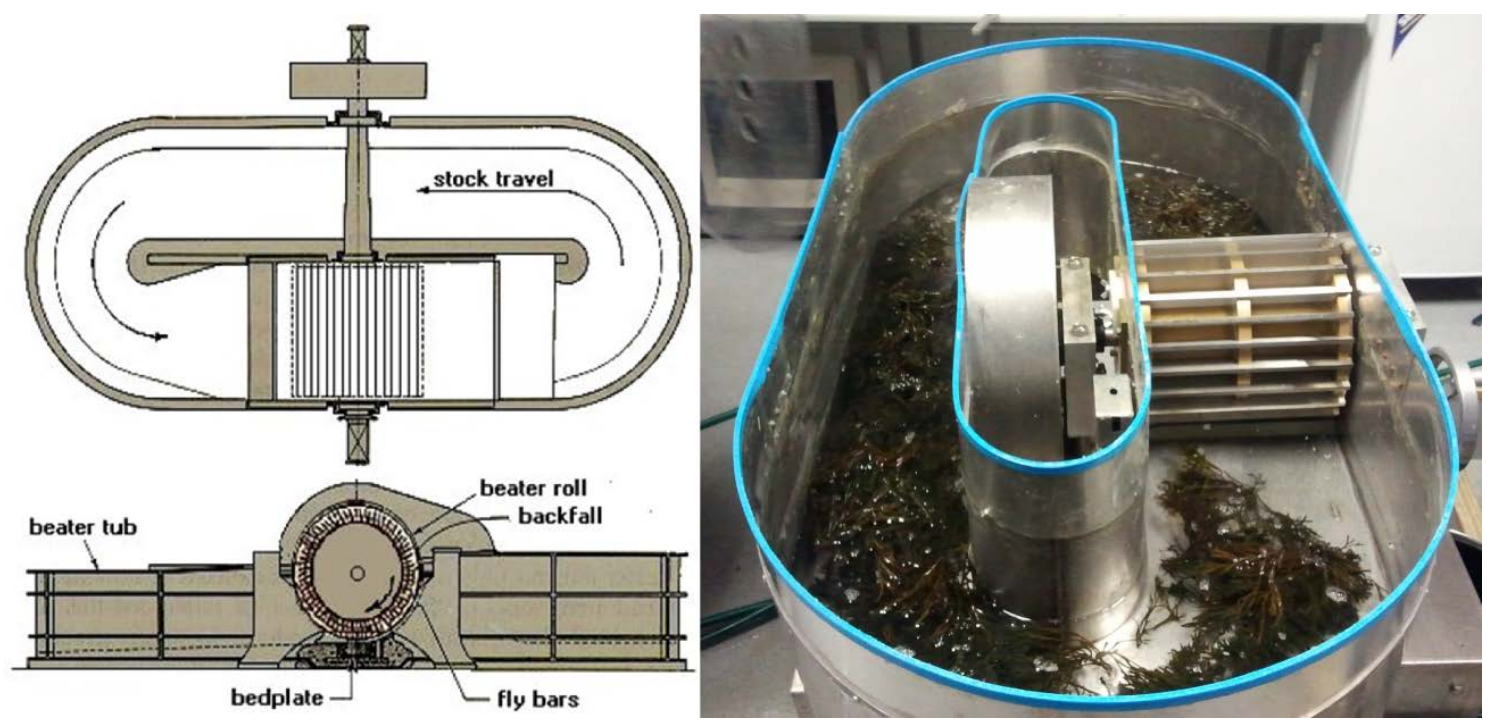

Figure 1 Hollander beater's working scheme and machine used in the experiment. 


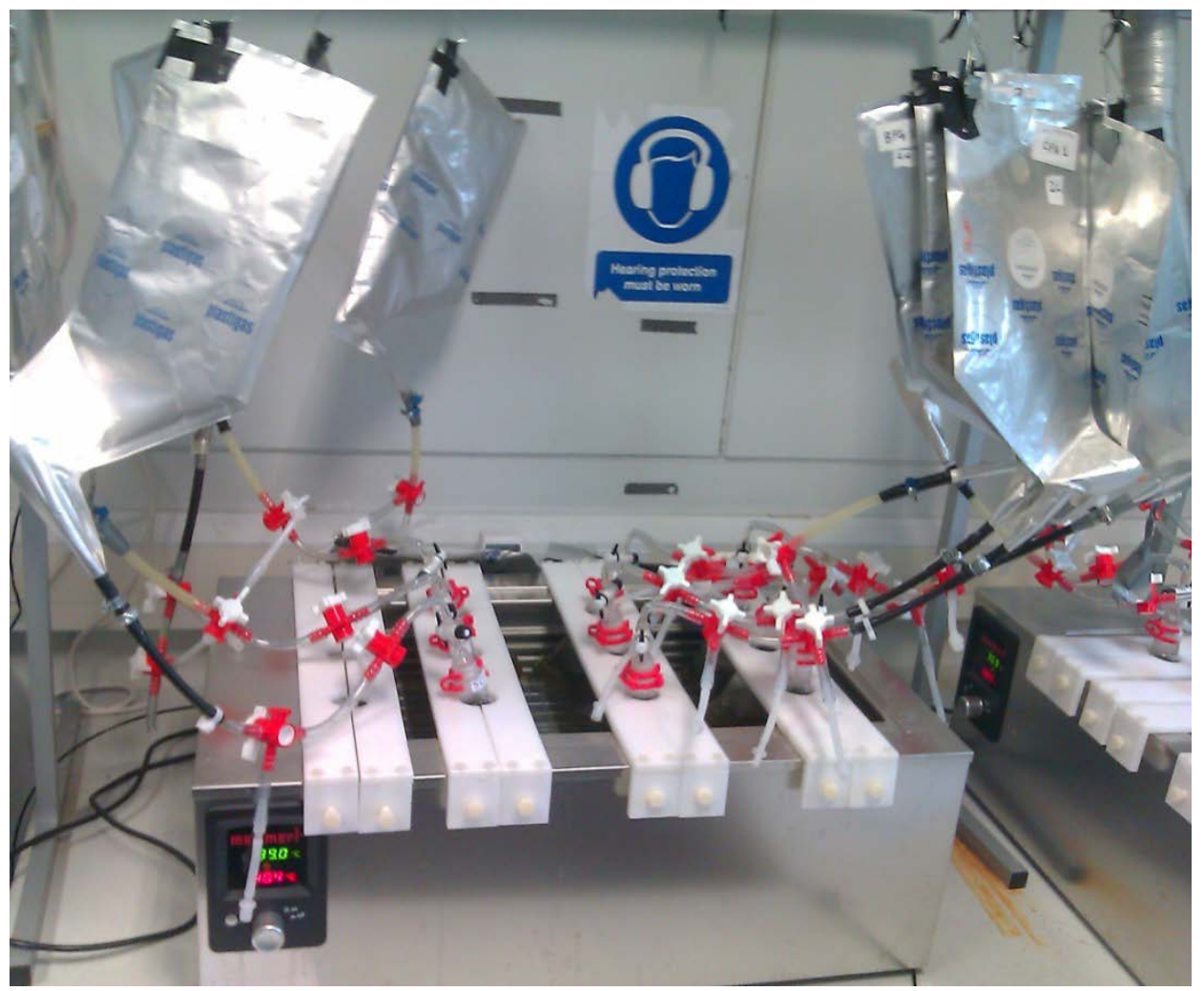

Figure 2 Heating units with reactors and collection bags. 


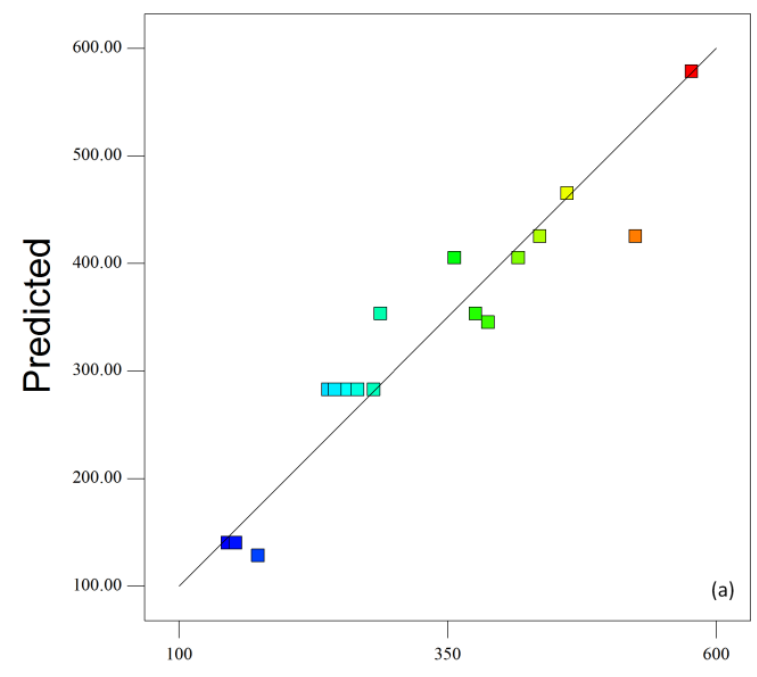

Actual

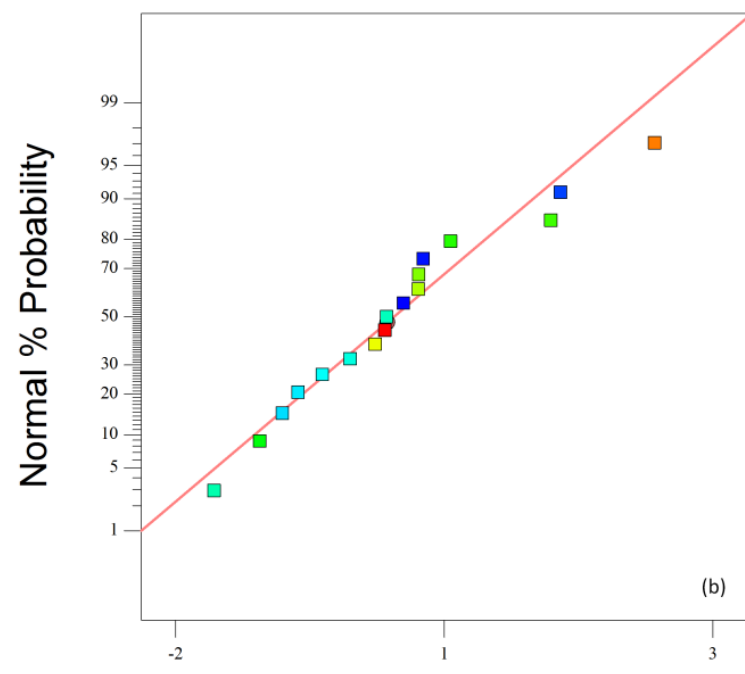

Internally Studentized Residuals

Figure 3 Scatter diagrams of biogas yields (a) and normal plot of residuals (b). 


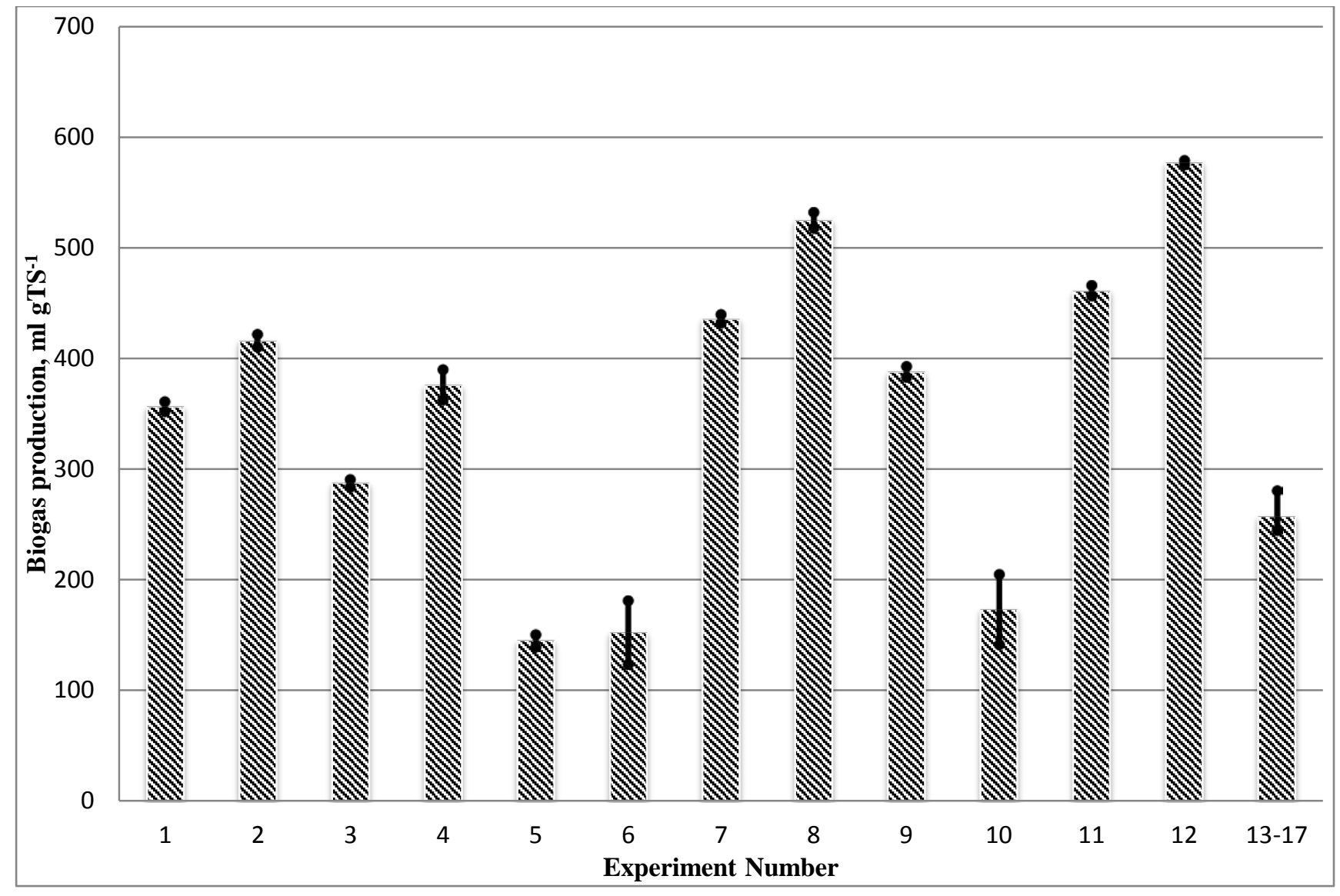

Figure 4 Bar-diagram of biogas yields with standard deviation values. 


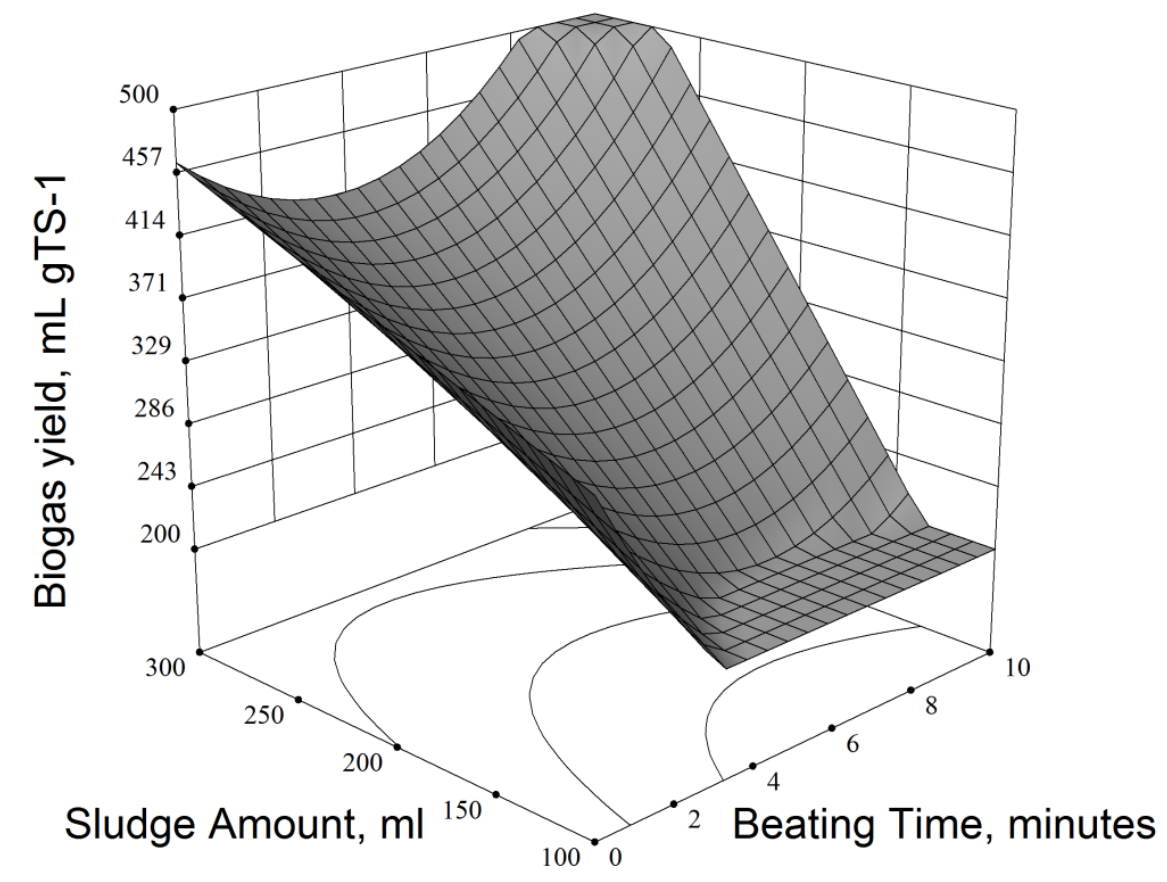

Figure 5: Response surface plot for biogas yield. 


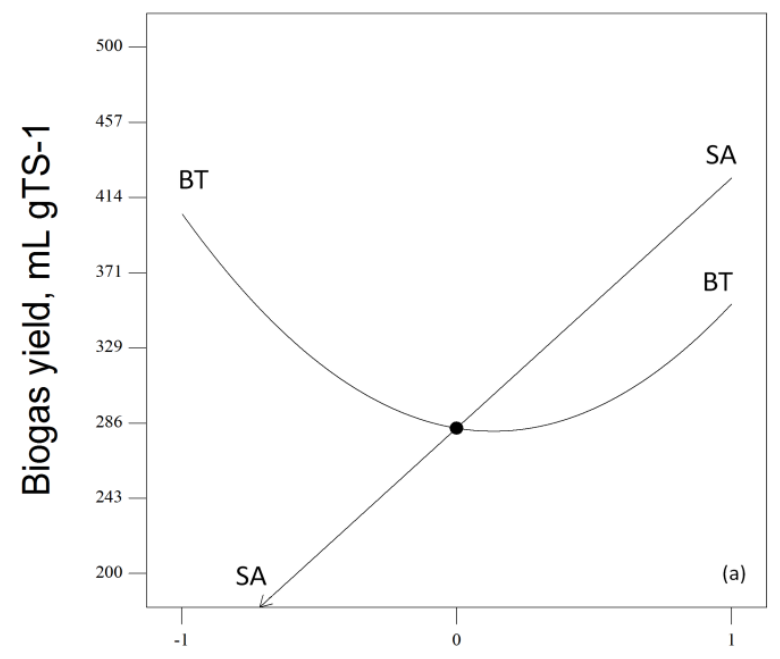

Deviation from Reference Point (Coded Units)

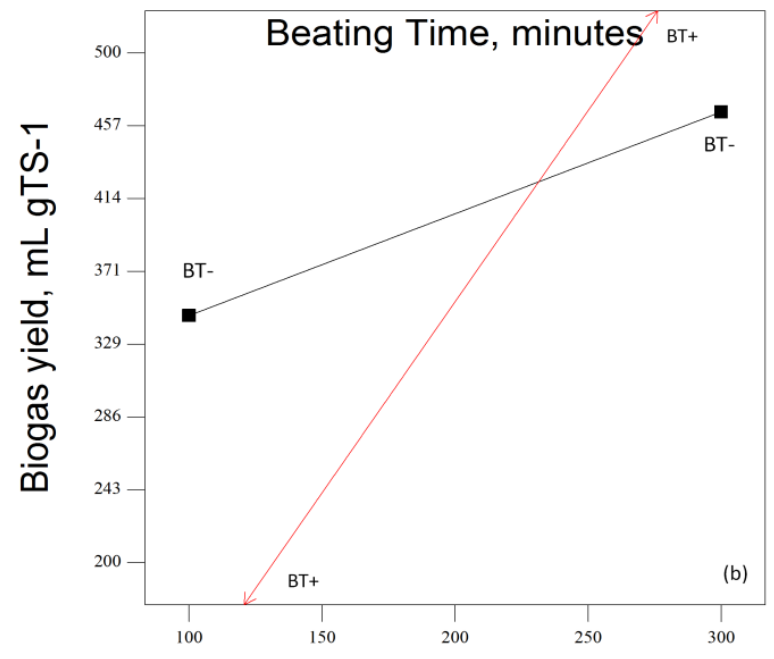

Sludge Amount, $\mathrm{ml}$

Figure 6 Perturbation plot (a) show the effect of process parameters on biogas volume; Interaction plot (b) showing the effect between sludge amount (SA) and beating time (BT) on response. 


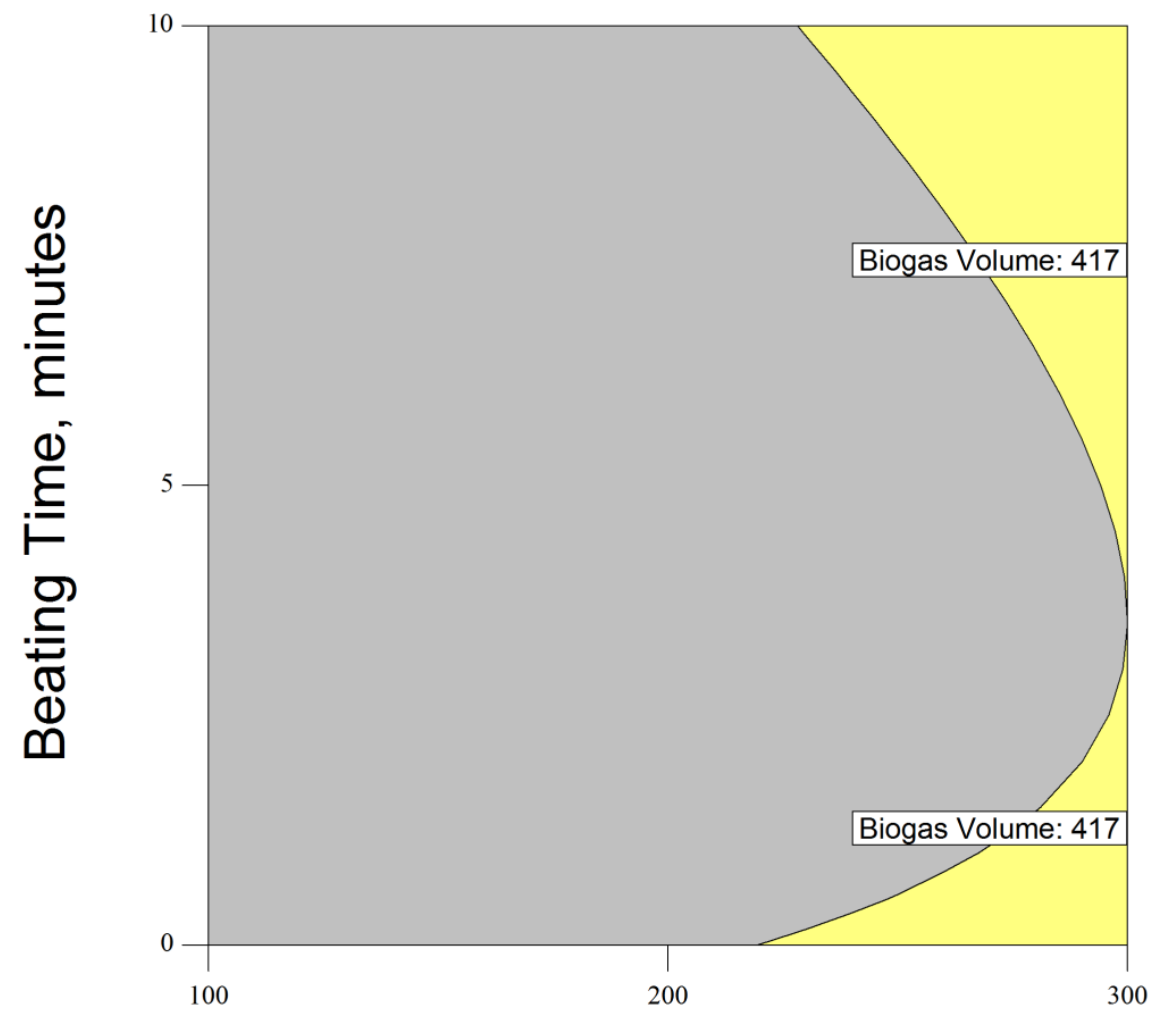

Sludge Amount, ml

Figure 7 Optimum zone with highest software-estimated biogas yields between 417 mL gTS-1 and $579 \mathrm{~mL} \mathrm{gTS}^{-1}$ at $\mathrm{T}=35^{\circ} \mathrm{C}$. 